\title{
Life-space assessment and associated clinical factors: SABE Colombia
}

\author{
Avaliação do espaço de vida e fatores \\ clínicos associados: SABE Colômbia
}

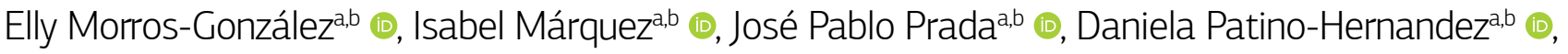 \\ Diego Chavarro-Carvajala,b ${ }^{\mathrm{a}}$, Carlos Cano-Gutiérrez ${ }^{\mathrm{a}, \mathrm{b}}$ ()
}

OBJECTIVES: Our aim was to assess whether an association exists between chronic diseases or multimorbidity and limited life space in older adults. METHODS: This is a secondary analysis of the SABE (Salud, Bienestar y Envejecimiento) Colombia Study. We assessed chronic diseases through self-report, and a limited life space was defined as any score $\leq 60$ in the Life-Space $\vdash \quad$ Assessment scale. Multimorbidity was defined as having two or more coexisting diseases. We performed bivariate analyses and multivariate logistic regressions aiming to obtain odds ratios with 95\% confidence intervals. RESULTS: The prevalence of limited life space was $2.95 \%$ with a mean score of $76.27 \pm 19.34$. Statistically significant associations were found between limited life space and mental disease (OR 1.45; 95\%Cl 1.15 - 1.82) and between limited life space and multimorbidity (OR 1.32; 95\%CI 1.06 - 1.63). CONCLUSIONS: Mental disease and multimorbidity are associated with limited life space in older adults. Therefore, preventing, diagnosing, and treating mental illness should be sought in addition to the existing preventive and therapeutic approaches available for noncommunicable diseases.

KEYWORDS: geriatric assessment, movement, multimorbidity, aged, Colombia.

OBJETIVO: Nosso objetivo foi avaliar se existe uma associação entre doenças crônicas ou multimorbidade e espaço de vida limitado em idosos. METODOLOGIA: Esta é uma análise secundária do Estudo SABE (Salud, Bienestar y Envejecimiento) Colômbia. Avaliamos as doenças crônicas por meio de autorrelato, e espaço de vida limitado foi definido como uma pontuação $\leq 60$ na escala do Life-Space Assessment. Multimorbidade foi definida como a coexistência de duas ou mais doenças. ○ Realizamos análises bivariadas e regressões logísticas multivariadas com o objetivo de obter odds ratios com intervalos de $\sum$ confiança de 95\%. RESULTADOS: A prevalência de espaço de vida limitado foi de 2,95\% com pontuação média de 76,27 \pm 19,34. Associações estatisticamente significativas foram encontradas entre espaço de vida limitado e doença mental (OR 1,45; IC95\% 1,15 - 1,82) e entre espaço de vida limitado e multimorbidade (OR 1,32; IC95\% 1,06 - 1,63). CONCLUSÕES: A doença mental e a multimorbidade estão associadas ao espaço de vida limitado em idosos. Portanto, deve-se buscar formas de prevenir, diagnosticar e tratar doenças mentais além das abordagens preventivas e terapêuticas atualmente disponíveis para doenças não transmissíveis.

PALAVRAS-CHAVE: avaliação geriátrica, movimento, multimorbidade, idoso, Colômbia.

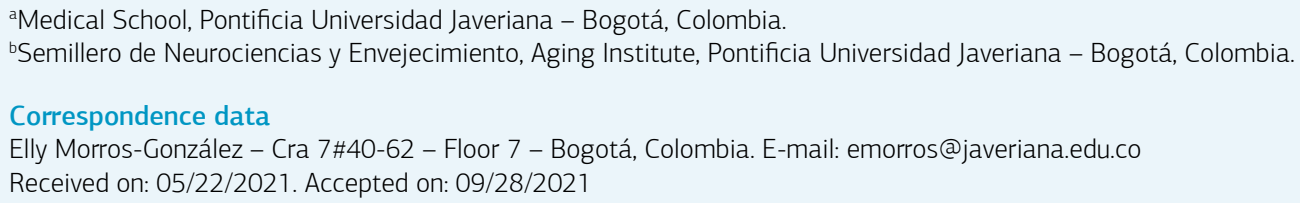

How to cite this article: Morros-González E, Márquez I, Prada JP, Patino-Hernandez D, Chavarro-Carvajal D, Cano-Gutiérrez C. Life-space assessment and associated clinical factors: SABE Colombia. Geriatr Gerontol Aging. 2021;15:e0210043. https://doi.org/10.53886/gga.e0210043 https://doi.org/10.53886/gga.e0210043 


\section{INTRODUCTION}

Latin America and the Caribbean have experienced changes in demographic patterns of aging for the past 50 years or so. These patterns have led to a sustained increase in the mean ages of population and in the overall speed of aging in the region. ${ }^{1}$ Colombia is a country with approximately $11 \%$ of the population being aged 60 and older. ${ }^{2}$ As such, maintaining quality of life as people age is an important public health goal.

Mobility is crucial for the development of life and indispensable for the comprehension of health and well-being of older adults. ${ }^{3}$ Life space is the spatial extent of mobility of individuals between environments; its range could go from one's bedroom to any region of the country facing environmental challenges. ${ }^{4}$ Thus, the assessment of life space could be considered as the outcome of any functional ability interaction with some environmental, social network, educational, and socioeconomical circumstances. ${ }^{5}$

It has been described that deterioration in mobility is associated with decreased functional ability ${ }^{6}$ health decline, ${ }^{7}$ and increased mortality. ${ }^{8}$ Therefore, the purpose of this study was to assess clinical factors and their association with a limited life space using data derived from the SABE (Salud, Bienestar y Envejecimiento/Health, Well-being, and Aging) 2015 Colombia study.

\section{METHODS}

Setting and participants

This study is a secondary analysis of the SABE 2015 Colombia study, a population-based cross-sectional study that included 23694 subjects aged 60 years or more, which was representative of the Colombian population. The study included a questionnaire covering active aging determinants, a subsample survey among caregivers, and a qualitative study regarding gender and cultural perspectives on quality of life. More information on this database can be found elsewhere. ${ }^{9}$

\section{Variables}

\section{Dependent variables}

We employed the score obtained in the Life-Space Assessment (LSA) scale as the dependent variable. This variable was created by asking the interviewed subjects how often they had traveled within each of six levels, ranging from 0 (not leaving the bedroom) to 5 (circulating to places outside their hometown), within the last 4 weeks (Figure 1). For each level, frequency and value of independence were

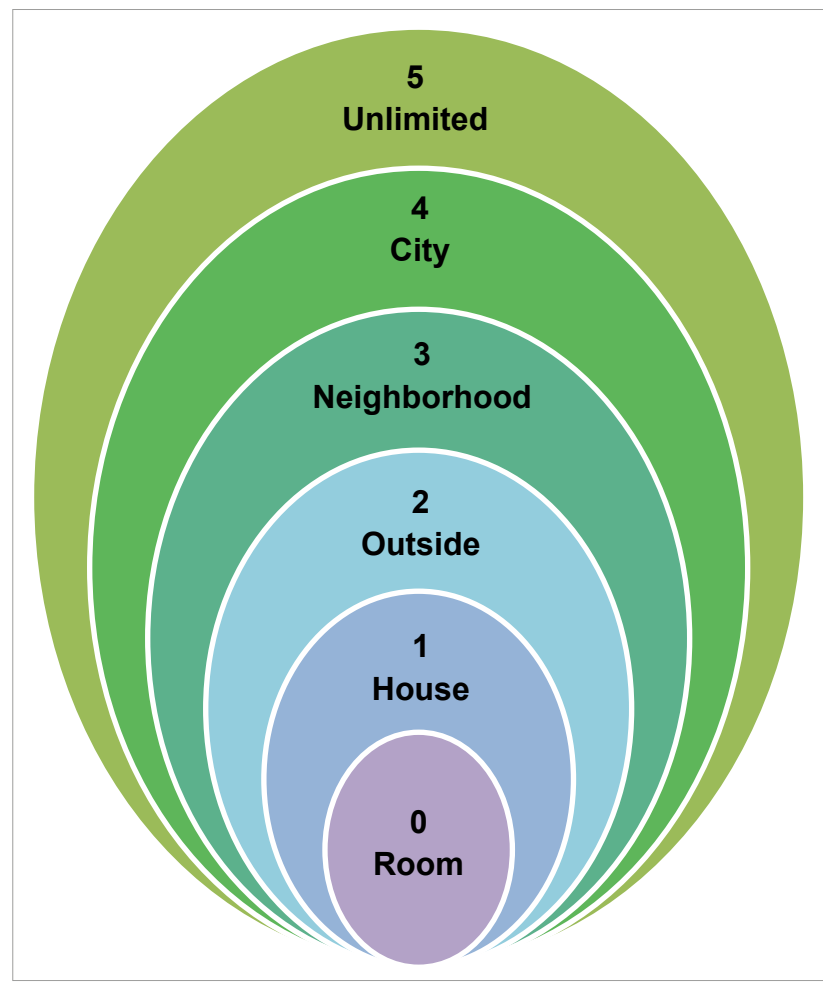

Figure 1. Life-space scheme.

assessed, and a partial LSA score was obtained as a product of level of the living space, level of independence, and frequency. The final LSA variable was defined as the sum of all partial LSA scores (Figure 2). Frequency of transportation to each level ranged from 1 (less than once a week) to 4 (every day). The value of independence had three possible scores: 2 (not requiring assistance), 1.5 (requiring equipment usage), and 1 (requiring help from someone else), according to previously validated methods for Latin American subjects. ${ }^{5}$ We further dichotomized our variable into two groups, those with a total score below 60 were categorized as having a limited life space, and those with a total score equal to or above 60 were considered as having a nonlimited life space.

\section{Independent variables}

Our main independent variables were multimorbidity and individual diseases. The presence of diseases was assessed by inquiring the participants, "Have you been diagnosed with...?" for each of the following comorbidities: hypertension, diabetes mellitus, cancer (any type), chronic obstructive pulmonary disease, myocardial infarction, stroke, arthritis/osteoarthrosis, mental illnesses (any self-reported mental illness), and ulcers/ skin lesions. Multimorbidity was defined as the presence of 2 or more coexisting diseases in an individual. 


\begin{tabular}{|c|c|c|c|c|c|}
\hline \multicolumn{6}{|l|}{ Life-space scale } \\
\hline \multicolumn{2}{|l|}{ Level of life space } & \multicolumn{2}{|l|}{ Frequency } & \multicolumn{2}{|c|}{ Independence } \\
\hline \multicolumn{2}{|c|}{ During the last 4 weeks, you've been... } & \multicolumn{2}{|c|}{ How many times? } & \multicolumn{2}{|c|}{$\begin{array}{l}\text { Have you needed assistance from } \\
\quad \text { another person? } \\
\text { Have you used any support devices? }\end{array}$} \\
\hline \multirow{4}{*}{$\begin{array}{l}\text { In other rooms in the house } \\
\text { besides where you sleep. }\end{array}$} & \multirow{4}{*}{$\begin{array}{l}\text { Yes: } 1 \rightarrow \\
\text { No: } 2 \downarrow\end{array}$} & Less than 1 time/week & 1 & From another & 1 \\
\hline & & $1-3$ times & 2 & \multirow{2}{*}{ Use of device } & \multirow{2}{*}{1.5} \\
\hline & & $4-6$ times & 3 & & \\
\hline & & Daily & 4 & None* & 2 \\
\hline \multirow{4}{*}{$\begin{array}{l}\text { In areas outside your house like } \\
\text { a terrace or patio, the hallway } \\
\text { of your building, garage or your } \\
\text { own garden or at the entrance } \\
\text { of your house. }\end{array}$} & \multirow{4}{*}{$\begin{array}{l}\text { Yes: } 1 \rightarrow \\
\text { No: } 2 \downarrow\end{array}$} & Less than 1 time/week & 1 & From another & 1 \\
\hline & & $1-3$ times & 2 & \multirow{2}{*}{ Use of device } & \multirow{2}{*}{1.5} \\
\hline & & $4-6$ times & 3 & & \\
\hline & & Daily & 4 & None* & 2 \\
\hline \multirow{4}{*}{$\begin{array}{l}\text { In places in your neighborhood } \\
\text { other than your own garden or } \\
\text { building. }\end{array}$} & \multirow{4}{*}{$\begin{array}{l}\text { Yes: } 1 \rightarrow \\
\text { No: } 2 \downarrow\end{array}$} & Less than 1 time/week & 1 & From another & 1 \\
\hline & & $1-3$ times & 2 & \multirow{2}{*}{ Use of device } & \multirow{2}{*}{1.5} \\
\hline & & $4-6$ times & 3 & & \\
\hline & & Daily & 4 & None * & 2 \\
\hline \multirow{4}{*}{$\begin{array}{l}\text { In places outside the } \\
\text { neighborhood but within the city. }\end{array}$} & \multirow{4}{*}{$\begin{array}{l}\text { Yes: } 1 \rightarrow \\
\text { No: } 2 \downarrow\end{array}$} & Less than 1 time/week & 1 & From another & 1 \\
\hline & & $1-3$ times & 2 & \multirow{2}{*}{ Use of device } & \multirow{2}{*}{1.5} \\
\hline & & $4-6$ times & 3 & & \\
\hline & & Daily & 4 & None* & 2 \\
\hline \multirow{4}{*}{ In places outside the city. } & \multirow{4}{*}{$\begin{array}{l}\text { Yes: } 1 \rightarrow \\
\text { No: } 2 \downarrow\end{array}$} & Less than 1 time/week & 1 & From another & 1 \\
\hline & & $1-3$ times & 2 & \multirow{2}{*}{ Use of device } & \multirow{2}{*}{1.5} \\
\hline & & $4-6$ times & 3 & & \\
\hline & & Daily & 4 & None* & 2 \\
\hline
\end{tabular}

Adapted from Espacio de vida. Encuesta SABE Colombia. ${ }^{14}$

*Neither help from another, neither use of devices.

Figure 2. Life-space scale.

\section{Statistical analysis}

Initially, we used a univariate analysis to explore extreme values and assess normal distribution, as well as to adjust and categorize variables. Regarding descriptive statistics, categorical variables were described through frequencies and percentages, while standard deviations and means were used for continuous variables. Afterwards, a bivariate analysis was performed through chi-square tests for categorical variables and Student's $t$-test for continuous variables.

Finally, we performed two logistic regressions for this study, which were fitted to obtain odds ratios (ORs) with $95 \%$ confidence intervals ( $95 \% \mathrm{CIs}$ ) of having a limited life space when having individual diseases and when displaying multimorbidity. Both analyses were performed twice, before and after adjustment for confounding variables. These confounding variables were sex, age, access to the healthcare system, and socioeconomic status. Both estimates are presented. The statistical level of significance was set at $\mathrm{p}<0.05$. Data were analyzed on STATA $12^{\circledR}$.

\section{RESULTS}

Regarding the characteristics of our sample population (Table 1), a total of 13582 women and 10112 men were analyzed, and 669 subjects were excluded because of missing data. The mean ages of subjects with limited vs. nonlimited life space were 71.6 vs. 70.9 years, respectively, with female subjects having a limited life-space frequency of $67.6 \%$ against $32.3 \%$ in the male population. The majority of patients classified as having a limited life space did not live alone, and the distribution of patients affiliated to the health care system was equitable. Also, $47.5 \%$ of subjects with a limited life 
space had a self-payable affiliation, while $48.2 \%$ of subjects in the same category had a subsidized affiliation. The mean number of years of education between subjects with a limited vs. nonlimited life space was similar, and the majority of subjects had a low socioeconomic status.

When considering individual comorbidities adjusted for limited and nonlimited life space in the bivariate analysis (Table 2), hypertension, diabetes, arthritis, and mental illness yielded statistically significant differences as diseases varying substantially between those with a limited life space and those without. Logistic regression analyses revealed associations between limited life space and arthritis as well as between limited life space and mental illness (OR 1.29, 95\%CI 1.09-1.52, $\mathrm{p}=0.003$; and OR $1.49,95 \% \mathrm{CI} 1.19-1.87, \mathrm{p}=0.001$, respectively). However, after adjustment for confounding variables (age, sex, socioeconomic status, and health care access), only mental illness maintained a statistically significant association with limited life space (OR 1.45, 95\%CI 1.15 - 1.82, $\mathrm{p}=0.002)$ (Table 3).

Table 1. Sample characteristics stratified by life space limitation ( $n=22$ 995).

\begin{tabular}{|c|c|c|c|}
\hline Variable & Limited LS & Nonlimited LS & p-value \\
\hline \multicolumn{4}{|l|}{ Sex } \\
\hline Women & $473(67.67 \%)$ & 13109 (57.01\%) & $<0.001$ \\
\hline \multicolumn{4}{|l|}{ Age } \\
\hline $60-70$ & 323 (46.21\%) & $11778(51.22 \%)$ & \multirow{4}{*}{0.01} \\
\hline $71-80$ & $258(36.91 \%)$ & 7998 (34.78\%) & \\
\hline$>80$ & $118(16.88 \%)$ & 3219 (14\%) & \\
\hline Mean (SD) & 71.63 (8.06) & 70.79 (8.20) & \\
\hline \multicolumn{4}{|l|}{ Living alone } \\
\hline Yes & $48(6.87)$ & $2172(9.45)$ & \multirow{2}{*}{0.02} \\
\hline No & 651 (93.13) & 20823 (90.55) & \\
\hline \multicolumn{4}{|c|}{ Health care system } \\
\hline Nonaffiliated & 16 (2.29\%) & 496 (2.16\%) & \multirow{4}{*}{$<0.001$} \\
\hline $\begin{array}{l}\text { Self-payable } \\
\text { affiliation }\end{array}$ & 332 (47.50\%) & 8295 (36.11\%) & \\
\hline $\begin{array}{l}\text { Subsidized } \\
\text { affiliation }\end{array}$ & 337 (48.21\%) & 13823 (60.18\%) & \\
\hline Other & $14(2 \%)$ & 357 (1.55\%) & \\
\hline \multicolumn{4}{|c|}{ Years of education } \\
\hline Mean (SD) & $4.77(8.33)$ & $4.26(8.78)$ & \\
\hline \multicolumn{4}{|c|}{ Socioeconomic status } \\
\hline Low & 550 (78.68\%) & 18796 (81.74\%) & \multirow{3}{*}{0.006} \\
\hline Middle & 138 (19.74\%) & $4043(17.58 \%)$ & \\
\hline High & 11 (1.57\%) & $156(0.68 \%)$ & \\
\hline
\end{tabular}

LS: life space; SD: standard deviation.
We further analyzed the presence of multiple comorbidities within the same subject with a logistic regression model (Table 4). In this case, both the unadjusted and adjusted analyses for age, sex, socioeconomic status, and health care access yielded a statistically significant association between limited life space and multimorbidity (OR 1.40, 95\%CI $1.14-1.74, \mathrm{p}=$ 0.02 ; and OR 1.32, 95\% CI 1.06-1.63, p = 0.01, respectively).

Table 2. Comorbidities and life-space assessment ( $n=22$ 995).

\begin{tabular}{l|c|c|c} 
& Limited LS & Nonlimited LS & p-value \\
Hypertension & $423(60.52 \%)$ & $12267(53.45 \%)$ & $<0.001$ \\
\hline Diabetes & $141(20.2 \%)$ & $3752(16.38 \%)$ & 0.007 \\
\hline Cancer & $36(5.15 \%)$ & $1002(4.36 \%)$ & 0.31 \\
\hline COPD & $83(11.87 \%)$ & $2340(10.20 \%)$ & 0.14 \\
\hline Ml & $108(15.57 \%)$ & $3126(13.61 \%)$ & 0.15 \\
\hline Stroke & $26(3.73 \%)$ & $1054(4.59 \%)$ & 0.28 \\
\hline Arthritis & $228(32.62 \%)$ & $5930(25.84 \%)$ & $<0.001$ \\
\hline Mental illness & $90(12.91 \%)$ & $1923(8.39 \%)$ & $<0.001$ \\
\hline Skin lesions & $51(8.84 \%)$ & $1448(7.6 \%)$ & 0.27 \\
\hline Amputation & $11(1.57 \%)$ & $409(1.78 \%)$ & 0.68
\end{tabular}

LS: life space; COPD: chronic obstructive pulmonary disease; MI: myocardial infarction.

Table 3. Logistic Regression regarding life-space assessment and individual comorbidities ( $\mathrm{n}=22$ 995).

\begin{tabular}{l|c|c}
\multirow{2}{*}{} & $\begin{array}{c}\text { Unadjusted } \\
\text { analysis }\end{array}$ & Adjusted analysis \\
\cline { 2 - 3 } & \multicolumn{2}{|c}{ Odds ratio $(95 \% \mathrm{CI})$} \\
\hline Hypertension & $1.25(1.06-1.40)$ & $1.16(0.99-1.36)$ \\
\hline Diabetes & $1.89(0.98-1.44)$ & $1.16(0.95-1.40)$ \\
\hline Arthritis & $1.29(1.09-1.52)^{*}$ & $1.16(0.98-1.37)$ \\
\hline Mental illness & $1.49(1.19-1.87)^{*}$ & $1.45(1.15-1.82)^{*}$ \\
\hline
\end{tabular}

*Statistically significant result.

${ }^{\S}$ Adjusted by age, sex, socioeconomic status and health care access. 95\% Cl: 95\% confidence interval.

Table 4. Logistic regression regarding life-space assessment and multimorbidity ( $\mathrm{n}=22$ 995).

\begin{tabular}{l|c|c}
\multirow{2}{*}{ Variable } & $\begin{array}{c}\text { Unadjusted } \\
\text { analysis }\end{array}$ & $\begin{array}{c}\text { Adjusted } \\
\text { analysis }\end{array}$ \\
\cline { 2 - 3 } & \multicolumn{2}{|c}{ Odds ratio $(95 \% \mathrm{Cl})$} \\
\hline Multimorbidity & $1.40(1.14-1.74)^{*}$ & $1.32(1.06-1.63)^{*}$ \\
\hline
\end{tabular}

*Statistically significant result.

${ }^{\S}$ Adjusted by age, sex, socioeconomic status and health care access. 95\%Cl: 95\% confidence interval. 95\%Cl: 95\% confidence interval. 


\section{DISCUSSION}

There are few studies around the world contemplating the LSA scale and its association with clinical factors. However, Curcio et al..$^{5}$ recently made a clinical validation in Colombia. Our group collected data from a representative sample of individuals aged 60 years or more. The current study reports that $2.95 \%$ of the participants had a limited life space, and that it was significantly associated with multimorbidity and mental disorder after adjusting for confounding variables. People with a limited life space were mainly women aged between 60 and 70 years. More than half of these subjects were living with two or more people and were at the two lowest socioeconomic strata, which made them more likely to be part of the subsidized health care regimen.

Interestingly, we found in the multivariate analysis that the presence of any type of mental illness was the only clinical factor significantly associated with limited life space. This seems a relevant issue because many physicians forget to assess the mental domain during a routine medical visit and tend to focus on clinically measurable signs and conditions.

Mental disorders in adults, mainly depression, anxiety, and bipolar disorder, have a negative impact on disability-adjusted life years (DALYs). ${ }^{10}$ In addition, mental disorders have been related to higher expenditure, financial dependence, decrease in work productivity, worse quality of life, and social limitations. The Encuesta Nacional de Salud Mental (National Mental Health Survey) 2015 yielded a prevalence of $2.2 \%$ related to some degree of mental disorder in people aged 45 or older, and it also documented the presence of mental disease related to chronic conditions such as hypertension, obesity, and rheumatic diseases, which relate to functional limitations and possibly a limited life space. ${ }^{10}$ Daré et al. ${ }^{11}$ showed a $54.4 \%$ prevalence of depression in patients with chronic obstructive pulmonary disease as well as a $16.2 \%$ prevalence of diabetes and/or obesity in patients with bipolar disorder in the Canadian population. This is in line with our results and suggests an alarming association of mental illness with chronic conditions. Therefore, interventions aimed at screening, preventing, and treating mental disease should be implemented.

The mean LSA score in our study $(76.27 \pm 19.34)$ was similar to those of previous reports—scores of 64 in the Finnish population $^{12}$ and 41 in a Mexican-American population. ${ }^{13}$ Although it had a wide range, our mean score was higher compared to that of the European study, possibly because of participants' high functionality. A previous report ${ }^{14}$ described that $79 \%$ of the population is independent in activities of daily living and $62 \%$ carry out instrumental activities without any difficulty. Limited life space is related not only to clinical conditions but also to environmental factors such as infrastructure of the neighborhood, crime rate/insecurity, and gender roles. Said factors were not possible to measure and could be a source of bias, and they partly explain the predominance of women in our sample of participants with a limited life space.

Our study has several strengths; we reported prevalence rates for limited life space in a representative sample of older adults living across Colombia. These data allowed us to describe valuable associations for policymakers and for the design of much needed interventions to benefit older adults. In addition, we used a tool that can easily assess mobility and is validated in our country and in multiple others around the world. As such, it may be a useful complement for functional evaluation in older adults. However, there are some limitations; this is a cross-sectional study, therefore causality cannot be determined. There is no information on the classification of mental disease or its severity, and we cannot confirm if social limitation is due to mental disease. Also, every clinical variable evaluated was self-reported.

\section{CONCLUSION}

Limited life space in older age is an important concern in Colombia and is associated with mental health and multimorbidity. Therefore, preventing, diagnosing, and treating mental illness should be sought in addition to the existing preventive and therapeutic approaches available for noncommunicable diseases. Further research within this population is paramount to design better health care interventions and public health policies.

\section{CONFLICT OF INTERESTS}

The authors declare that they have no affiliations or involvement in any organization with financial or commercial interest in the subject matter discussed in this manuscript.

\section{FUNDING}

This research did not receive any specific grant from funding agencies in the public, commercial, or not-for-profit sectors.

\section{AUTHORS' CONTRIBUTION}

EM: conceptualization, data curation, project administration, resources, writing - original draft. IM: data curation, project administration, writing - original draft. JPP: conceptualization, investigation, resources. DP: data curation, methodology, writing - original draft. DCC: methodology, writing - review \& editing, supervision. CCG: methodology, writing - review \& editing, supervision. 


\section{REFERENCES}

1. Palloni A, Pinto-Aguirre G, Pelaez M. Demographic and health conditions of ageing in Latin America and the Caribbean. Int J Epidemiol. 2002;31(4):762-71. http://doi.org/10.1093/ije/31.4.762

2. Ministerio de Salud y Protección Social de Colombia. Sala situacional de la Población Adulta Mayor. Available from: https://www.minsalud. gov.co/sites/rid/Lists/BibliotecaDigital/RIDE/DE/PS/sala-situacionenvejecimiento-2018.pdf. Accessed on May 21, 2021.

3. Siordia C. A critical analysis of the internal logic in the LifeSpace Assessment (LSA) composite score and suggested solutions. Clin Rehabil. 2016;30(6):604-16. http://doi. org/10.1177/0269215515592251

4. Uemura K, Shimada H, Makizako H, Yoshida D, Doi T, Yamada M, et al. Factors associated with life-space in older adults with amnestic mild cognitive impairment. Geriatr Gerontol Int. 2013;13(1):161-6. http://doi.org/10.1111/j.1447-0594.2012.00878.x

5. Curcio CL, Alvarado BE, Gomez F, Guerra R, Guralnik J, Zunzunegui MV. Life-Space Assessment scale to assess mobility: validation in Latin American older women and men. Aging Clin Exp Res. 2013;25(5):553-60. http://doi.org/10.1007/s40520-013-0121-y

6. Murata C, Kondo T, Tamakoski K, Yatsuya H, Toyoshima H. Factors associated with life space among community-living rural elders in Japan. Public Health Nurs. 2006;23(4):324-31. http://doi.org/10.1111/ j.1525-1446.2006.00568.x

7. Portegijs E, Rantakokko M, Viljanen A, Sipilä S, Rantanen T. Identification of older people at risk of ADL disability using the life-space assessment: a longitudinal cohort study. J Am Med Dir Assoc. 2016;17(5):410-4. http://doi.org/10.1016/j.jamda.2015.12.010

8. Mackey DC, Cauley JA, Barrett-Connor E, Schousboe JT, Cawthon PM, Cummings SR. Life-space mobility and mortality in older men: a prospective cohort study. J Am Geriatr Soc. 2014;62(7):1288-96. http://doi.org/10.1111/jgs.12892

9. Gomez F, Corchuelo J, Curcio CL, Calzada MT, Mendez F. SABE Colombia: Survey on Health, Well-Being, and Aging in Colombia-Study Design and Protocol. Curr Gerontol Geriatr Res. 2016;2016:7910205. http://doi.org/10.1155/2016/7910205

10. Gómez-Restrepo C, de Santacruz C, Rodriguez MN, Rodriguez V, Tamayo Martínez N, Matallana D, et al. Encuesta Nacional de Salud Mental Colombia 2015. Protocolo del estudio. Rev Colomb Psiquiatr. 2016;45(Suppl. 1);2-8. https://doi.org/10.1016/j. rcp.2016.04.007

11. Daré LO, Bruand PE, Gérard D, Marin B, Lameyre V, Boumédiène F. et al. Co-morbidities of mental disorders and chronic physical diseases in developing and emerging countries: A meta-analysis. BMC Public Health. 2019;19(1):304. https://doi.org/10.1186/s12889019-6623-6

12. Portegijs E, Iwarsson S, Rantakokko M, Viljanen A, Rantanen T. Lifespace mobility assessment in older people in Finland; measurement properties in winter and spring. BMC Res Notes. 2014;7(1):1-9. https://doi.org/10.1186/1756-0500-7-323

13. Snih S Al, Peek K, Sawyer P, Markides K, Allman R. Life-space mobility among mexican americans aged 75 years and older. J Am Geriatr Soc. 2012;60(3):532-7. https://doi.org/10.1111/j.15325415.2011.03822.x

14. Ministerio de Salud y Protección Social de Colombia. Resumen: "Sabe Colombia 2015: Estudio Nacional de Salud, Bienestar y Envejecimiento". Available from: minsalud.gov.co/sites/rid/Lists/ BibliotecaDigital/RIDE/VS/ED/GCFI/Resumen-Ejecutivo-EncuestaSABE.pdf. Accessed on May 21, 2021. 